\title{
Pertambahan bobot badan sapi impor Brahman Cross heifers dan steers pada bobot kedatangan yang berbeda
}

\section{Average daily gain of Brahman Cross beef cattle imported for heifers and steer type at different arrival weights}

\section{Amam $^{1}$ dan Haryono ${ }^{2}$}

${ }^{1}$ Program Studi Peternakan, Fakultas Pertanian, Universitas Jember. Jl. Diponegoro, Poncogati, Curah Dami, Kabupaten Bondowoso, Jawa Timur 68251

${ }^{2}$ Supervisor Perusahaan Feedlot, Indonesia. Jl. Nyimas Endang Geulis No. 62, Desa Jemaras Lor, Kecamatan Klangenan, Kabupaten Cirebon 45165

*Email Koresponden: amam.faperta@unej.ac.id

\begin{tabular}{|c|c|}
\hline ARTICLE INFO & A B S T R A K \\
\hline $\begin{array}{l}\text { Received: } \\
22 \text { October } 2020\end{array}$ & $\begin{array}{l}\text { Impor sapi bakalan untuk memenuhi kebutuhan daging nasional telah diatur di } \\
\text { dalam Peraturan Menteri Pertanian Republik Indonesia Nomor } 108 / \text { Permentan/ }\end{array}$ \\
\hline $\begin{array}{l}\text { Accepted: } \\
27 \text { March } 2021\end{array}$ & $\begin{array}{l}\text { PD.410/9/2014. Penelitian ini bertujuan untuk mengkaji performa sapi impor yang } \\
\text { didatangkan dari Australia berdasarkan Pertambahan Bobot Badan (PBB). Observasi }\end{array}$ \\
\hline $\begin{array}{l}\text { Published: } \\
31 \text { March } 2021\end{array}$ & $\begin{array}{l}\text { dilakukan pada sapi impor bakalan dari bangsa Brahman Cross yang terdiri dari } 2 \\
\text { jenis, yaitu heifers dan steers. Fokus pengamatan pada PBB sapi dengan Bobot Datang } \\
\text { (BD) kisaran 200, 300, dan } 400 \mathrm{~kg} \text {. Sapi impor tersebut digemukkan di perusahaan } \\
\text { feedlot minimal selama } 106 \text { hari. Analisis data menggunakan analisis deskriptif dan } \\
\text { analisis independent samples test dengan program aplikasi IBM SPSS Statistics } 26 . \\
\text { Hasil penelitian menunjukkan bahwa PBB maksimal sapi impor bangsa Brahman } \\
\text { Cross jenis heifers pada berat kedatangan (BD) 200, 300, dan } 400 \text { kg masing-masing } \\
\text { ialah 2,01; } 1,81 \text {; dan } 1,45 \mathrm{~kg} \text { dengan rata-rata PBB masing-masing sebesar 1,40; } \\
1,17 \text {; dan } 1,10 \mathrm{~kg} \text {, sedangkan PBB maksimal untuk jenis steers pada berat kedatangan }\end{array}$ \\
\hline Kata kunci: & (BD) 200, 300, dan $400 \mathrm{~kg}$ masing-masing ialah 1,86; 2,53; dan 1,96 kg dengan rat \\
\hline Brahman cross & rata $\mathrm{PBB}$ masing-masing sebesar 1,44; 1,43; dan 1,43 kg. Kesimpulan menunjukka \\
\hline Heifers & bahwa sapi impor bangsa Brahman Cross jenis steers memiliki PBB lebih tinggi jika \\
\hline Sapi impor & oandingkan dengan jenis heifers. Saran untuk perusahaan importir sapi poton \\
\hline Sapi potong & kalan hendaknya memilih jenis steers pada berat kedatangan (BD) $300 \mathrm{~kg}$, seb \\
\hline Steers & i memiliki potensi PBB yang maksimal. \\
\hline
\end{tabular}

A B S T R A C T

The import of beef cattle to meet the national demand for meat has been regulated in the Regulation of the Minister of Agriculture of the Republic of Indonesia Number 108/ Permentan/PD.410 /9/2014. This study aims to assess the performance of imported cattle that came from Australia based on the Average Daily Gain (ADG). Observations were made on imported beef cattle from the Brahman Cross, which consisted of 2 types, namely heifers and steers. The focus of observation is on ADG of cattle with Come Weights (CW) ranging from 200, 300, and $400 \mathrm{~kg}$. The imported cattle are fattened at the feedlot company for at least 106 days. The data analysis used descriptive analysis and independent samples test with IBM SPSS Statistics 26 application program. The results showed that the maximum ADG of imported Brahman Cross cattle heifers at arrival weight (AW) 200,300, and $400 \mathrm{~kg}$ were $2.01 ; 1.81$; and $1.45 \mathrm{~kg}$ with an average

Keywords: Brahman cross Heifers Cattle imported Beef cattle Steers $A D G$ of $1.40 ; 1.17$; and $1.10 \mathrm{~kg}$, while the maximum $A D G$ for this type of steers at arrival weight (BD) 200,300, and $400 \mathrm{~kg}$ were 1.86; 2.53; and $1.96 \mathrm{~kg}$ with an average $A D G$ of 1.44 each; 1.43; and $1.43 \mathrm{~kg}$. The conclusion shows that the imported Brahman Crossbreeds of steers have a higher ADG than the heifers. Suggestions for cattle beef importing companies should choose the type of steers with an arrival weight (AW) of 300 $\mathrm{kg}$, because cattle had the maximum potential of $A D G$. 


\section{PENDAHULUAN}

Berbagai permasalahan utama usaha ternak sapi potong di tingkat peternak menyebabkan rendahnya produktivitas usaha peternakan rakyat (Harsita \& Amam, 2019). Kondisi tersebut diperburuk dengan lemahnya akses peternak terhadap berbagai sumber daya (Amam, Fanani, Hartono, \& Nugroho, 2019). Semakin mudah akses peternak terhadap sumber daya, maka potensi pengembangan usaha ternak semakin besar (Amam, Fanani, Hartono, \& Nugroho, 2019a). Amam, Fanani, Hartono, \& Nugroho (2019b) menyebutkan sumber daya terdiri dari sumber daya finansial, teknologi, dan fisik. Sumber daya juga meliputi sumber daya ekonomi, sumber daya lingkungan, dan sumber daya sosial (Amam, Jadmiko, Harsita, \& Yulianto, 2019). Aspek kerentanan juga dapat berpengaruh negatif terhadap sumber daya usaha ternak sapi potong (Amam, Yulianto, Widodo, \& Romadhona, 2020).

Usaha peternakan sapi potong rakyat nampaknya belum mampu berkembang dengan baik (Soetriono, Soejono, Zahrosa, Maharani, \& Amam, 2019), padahal menurut Setiawan, Hartono, dan Utami (2014) usaha peternakan sapi potong rakyat mampu memberikan kontribusi terhadap pendapatan rumah tangga peternak. Kondisi tersebut tentunya bertolak belakang dengan upaya pemerintah untuk swasembada daging sapi. Berbagai upaya telah dilakukan pemerintah untuk mensukseskan program swasembada daging sapi, diantaranya ialah larangan pemotongan betina produktif dan Upaya Khusus Sapi Indukan Wajib Bunting (UPSUS SIWAB) sesuai dengan Peraturan Menteri Pertanian Republik Indonesia (PERMENTAN) Nomor 48 Tahun 2016. Upaya tersebut mendukung pembibitan (breeding) sapi potong di Indonesia. Amam dan Harsita (2019) menyatakan bahwa pembibitan (breeding) merupakan salah satu pilar usaha ternak, selain pakan (feeding) dan manajemen (management).

Upaya lain yang dilakukan pemerintah untuk mendukung swasembada daging sapi di Indonesia ialah mendorong investasi swasta dan Badan Usaha Milik Negara (BUMN) untuk melakukan penambahan populasi sapi sesuai dengan Permentan No. 49 Tahun 2016 tentang Pemasukan Ternak Ruminansia Besar ke Wilayah Negera Republik Indonesia. Kondisi tersebut tentunya memberikan peluang bagi perusahaan feedlot untuk mendatangkan sapi bakalan impor dari luar negeri dengan tujuan untuk pemenuhan kebutuhan daging dalam negeri. Impor sapi bakalan untuk memenuhi kebutuhan daging nasional telah diatur di dalam PERMENTAN No. 108 Tahun 2014.

PERMENTAN No. 108 Tahun 2014 menyebutkan bahwa sapi bakalan adalah sapi (potong) bukan bibit yang memiliki sifat unggul untuk dipelihara selama kurun waktu tertentu untuk tujuan produksi daging. Salah satu negara pengimpor sapi bakalan ke Indonesia ialah Australia. Jenis sapi bakalan impor umumnya ialah bangsa (breed) Brahman Cross. Sapi bakalan Brahman Cross yang masuk ke Indonesia ialah jenis heifers dan steers. Sapi heifers merupakan sapi betina yang berumur 1 sampai 2 tahun dan belum memiliki keturunan (sapi dara), sedangkan sapi steers merupakan sapi jantan yang telah dikastrasi pada umur 6 sampai 24 bulan untuk tujuan penggemukan.

Sapi potong bakalan yang masuk ke Indonesia baik jenis heifers maupun steers umumnya memiliki bobot badan yang berbeda. Perbedaan bobot badan tersebut dipengaruhi oleh ketersediaan stock dari negara pengeskpor, yaitu Australia. McAlpine, Etter, Fearnside, Seabrook, \& Laurance (2009) menyebutkan Australia di bagian utara sering mengalami kemarau panjang dan kekeringan. Kondisi demikian berpengaruh terhadap ketersediaan sapi bakalan secara keseluruhan.

Tujuan penelitian ialah untuk mengkaji performa sapi bakalan impor yang didatangkan dari Australia berdasarkan Pertambahan Bobot Badan (PBB). Observasi dilakukan pada sapi impor bakalan dari bangsa Brahman Cross yang terdiri dari 2 jenis, yaitu heifers dan steers. Keterbaruan (novelty) dari penelitian ini ialah belum pernah dilakukan pengamatan mendalam mengenai performa sapi impor yang masuk ke Indonesia, data tersebut milik perusahaan feedlot sebagai pelaku usaha penggemukan sapi. Pentingnya penelitian ini sebagai salah satu rekomendasi untuk perusahaan importir sapi potong bakalan.

\section{MATERI DAN METODE}

Materi penelitian dilakukan dengan metode deskriptif. Nazir (2014) mengemukakan metode penelitian deskriptif bertujuan untuk membuat 
deskripsi, gambaran, atau lukisan secara sistematis, faktual, dan akurat mengenai sebuah fakta, sifat, maupun hubungan antar-fenomena yang diselidiki atau diamati. Pengamatan penelitian pada performa sapi bakalan impor yang didatangkan dari Australia berdasarkan Pertambahan Bobot Badan (PBB). Observasi dilakukan pada sapi impor bakalan dari bangsa Brahman Cross yang terdiri dari 2 jenis, yaitu heifers dan steers. Fokus pengamatan pada PBB sapi dengan Berat Datang (BD) kisaran 200, 300, dan $400 \mathrm{~kg}$. Sapi impor tersebut digemukkan di perusahaan feedlot minimal selama 106 hari. Analisis data menggunakan analisis deskriptif dengan program aplikasi IBM SPSS Statistics 26.

Pengamatan dilakukan pada 528 ekor sapi bakalan impor yang digemukkan secara serentak berdasarkan waktu kedatangan. Jumlah tersebut terdiri dari sapi heifers dengan bobot 200 sampai $300 \mathrm{~kg}$ sebanyak 73 ekor, bobot 300 sampai $400 \mathrm{~kg}$ sebanyak 144 ekor, dan bobot $>400 \mathrm{~kg}$ sebanyak 24 ekor, sedangkan sapi steers dengan bobot 200 sampai 300 kg sebanyak 25 ekor, bobot 300 sampai $400 \mathrm{~kg}$ sebanyak 218 ekor, dan bobot $>400 \mathrm{~kg}$ sebanyak 37 ekor, dan sisanya sebanyak 7 ekor sapi tidak masuk dalam pengamatan sebab merupakan sapi dalam kondisi sakit. Perbedaan Berat Datang (BD) sapi tersebut menyesuaikan dengan ketersediaan stock dari negara pengekspor.

\section{HASIL DAN PEMBAHASAN}

\section{Pertambahan Bobot Badan (PBB) Sapi Bakalan Impor Jenis Heifers}

Sapi jenis heifers dengan berat datang (BD) kisaran 200, 300, dan 400 kg yang digemukkan di perusahaan feedlot minimal selama 106 hari memiliki pertambahan bobot badan (PBB) yang dicantumkan pada Tabel 1.

Pertambahan bobot badan harian (PBBH) sapi potong dengan bobot badan $370 \mathrm{~kg}$ ialah $0,84 \mathrm{~kg} /$ hari dan maksimal ialah $1,25 \mathrm{~kg} /$ hari (Amien, 2013), namun jika dibandingkan dengan
PBB minimal sapi bakalan impor pada BD $>400$ kg memiliki PBB minimal lebih rendah yaitu 0,41 $\mathrm{kg} /$ hari. Hal tersebut disebabkan oleh 2 (dua) faktor utama, yaitu lamanya waktu pengangkutan dan berat bobot badan sapi. Semakin lama waktu tempuh saat pengangkutan (transportasi) menyebabkan sapi stres sehingga berdampak pada penurunan bobot badan.

Lamanya waktu tempuh dipengaruhi oleh beberapa faktor, diantaranya seperti cuaca saat di kapal laut, kondisi padatnya jalanan (macet) saat di Tanjung Priok hingga lokasi perusahaan, dan lamanya waktu tunggu ternak diangkut dari kapal menuju lokasi perusahaan sebab keterbatasan alat angkut. Kondisi tersebut berdampak pada rendahnya tingkat kesejahteraan hewan (Phillips, Holloway, Warrington, \& Venuto, 2009). Berat bobot badan sapi saat awal datang juga berpengaruh pada PBB. Semakin berat bobot badan sapi, maka penurunan bobot badan (penyusutan) akan semakin besar, meskipun menurut (Façanha et al., 2019) bahwa sapi Brahman Cross lebih kuat terhadap tekanan panas dan stres.

Sapi bakalan impor Brahman Cross heifers memiliki PBB tertinggi pada kisaran berat datang 200-300 kg yaitu sebesar 2,01 kg/hari dengan rata-rata PBB $1,44 \mathrm{~kg} /$ hari. Kondisi tersebut lebih tinggi jika dibandingkan dengan kisaran berat datang 300 sampai $400 \mathrm{~kg}$ dan $>400 \mathrm{~kg}$. Hal tersebut didukung oleh pernyataan Daigle et al. (2018) yang menyebutkan rata-rata PBB sapi Brahman Cross ialah 1,45 kg/hari untuk kisaran berat $200 \pm 11 \mathrm{~kg}$, sedangkan menurut (Brew et al., 2011) menyebutkan bahwa PBB sapi Brahman Cross sebesar 1,41 kg/hari.

Sapi bakalan impor Brahman Cross heifers pada berat datang 300 sampai $400 \mathrm{~kg}$ dan $>400$ kg memiliki PBB lebih rendah sebab secara reproduksi (sistem hormonal) sudah matang dan menginjak fase umur pubertas (Affandhy, Aryogi, \& Tiesnamurti, 2014), sapi heifers sudah dapat dikawinkan dan bunting meski tujuan pemeliharaannya sebagai sapi potong bukan

Tabel 1. Pertambahan Bobot Badan (PBB) sapi bakalan impor jenis heifers

\begin{tabular}{lccccc}
\hline Berat Datang $(\mathrm{kg})$ & Jumlah (ekor) & Minimal & Maksimal & Rata-rata & Simpangan Baku \\
\hline $200-300$ & 73 & 0,84 & 2,01 & 1,44 & 0,26 \\
$300-400$ & 144 & 0,52 & 1,81 & 1,17 & 0.25 \\
$>400$ & 24 & 0,41 & 1,45 & 1,1 & 0,21 \\
\hline
\end{tabular}

Sumber: Hasil output IBM SPSS Statistics 26 
Tabel 2. Pertambahan Bobot Badan (PBB) sapi bakalan impor jenis steers

\begin{tabular}{lccccc}
\hline Berat Datang (kg) & Jumlah (ekor) & Minimal & Maksimal & Rata-rata & $\begin{array}{c}\text { Simpangan } \\
\text { Baku }\end{array}$ \\
\hline $200-300$ & 25 & 0,97 & 1,86 & 1,44 & 0,23 \\
$300-400$ & 218 & 0,76 & 2,53 & 1,43 & 0,28 \\
$>400$ & 37 & 0,79 & 1,96 & 1,43 & 0,26 \\
\hline
\end{tabular}

Sumber: Hasil output IBM SPSS Statistics 26

sebagai indukan (bibit). Phillips et al. (2009) menyatakan bahwa heifers yang tidak dijual sebagai betina pengganti dapat disimpan dan dipelihara untuk menghasilkan daging.

\section{Pertambahan Bobot Badan (PBB) Sapi Bakalan Impor Jenis Steers}

Sapi jenis steers dengan berat datang kisaran 200, 300, dan $400 \mathrm{~kg}$ yang digemukkan di perusahaan feedlot minimal selama 106 hari memiliki PBB yang dicantumkan pada Tabel 2.

Firdausi, Susilawati, Nasich, dan Kuswati (2012) menyatakan pertambahan bobot badan harian (PBBH) sapi potong jenis Brahman Cross pada bobot badan $<300 \mathrm{~kg}$ adalah $1,33 \pm 0,37 \mathrm{~kg}$; bobot badan $300-350 \mathrm{~kg}$ adalah $1,24 \pm 0,35 \mathrm{~kg}$, dan bobot badan $>350 \mathrm{~kg}$ adalah $1,13 \pm 0,36 \mathrm{~kg}$, jika dibandingkan dengan sapi bakalan impor jenis steer untuk breed yang sama, yaitu Brahman Cross memiliki PBBH rata-rata lebih rendah.

Sapi bakalan impor Brahman Cross steers memiliki PBB tertinggi pada kisaran berat datang 300 sampai $400 \mathrm{~kg}$ yaitu sebesar 2,53 kg/hari dengan rata-rata PBB 1,43 kg/hari. Pertambahan bobot badan maksimal tersebut lebih tinggi jika dibanding dengan berat datang 200-300 kg dan $>400 \mathrm{~kg}$. Zajulie, Nasich, Susilawati, dan Kuswati (2015) menerangkan bahwa PBB tinggi akan menghasilkan produktivitas karkas tinggi, idealnya untuk jenis sapi Brahman Cross steers ialah pada umur pemotongan 2,5 sampai 3 tahun atau setara dengan bobot awal 300-400 kg.

Sapi bakalan impor Brahman Cross steers pada berat datang 200-300 kg dan $>400 \mathrm{~kg}$ memiliki PBB maksimal lebih rendah sebab pada kisaran berat datang 200 sampai $300 \mathrm{~kg}$ sapi masih mengalami pertumbuhan, sedangkan pada berat datang $>400 \mathrm{~kg}$ sapi cenderung mudah stres, nafsu makan berkurang, hingga mengalami penurunan bobot badan. Sapi Brahman Cross $>400 \mathrm{~kg}$ juga umumnya telah menunjukkan perkembangan sifat reproduksi sehingga dapat mempengaruhi PBB. Fields, Hentges Jr, dan Cornelisse (1982) menyatakan sapi jantan Brahman Cross mencapai pubertas pada usia $15,9 \pm 0,4$ bulan dengan berat badan $432 \pm 16 \mathrm{~kg}$. Kondisi tersebut juga nampaknya bertentangan dengan Permentan Nomor 108/2014 dalam Pasal 7 butir c yang menyebutkan bahwa berat badan per ekor maksimal $350 \mathrm{~kg}$ pada saat tiba di tempat pemasukan, dan berumur tidak lebih dari 30 (tiga puluh) bulan serta harus digemukkan minimal 60 (enam puluh) hari setelah selesai dilakukan tindakan karantina.

\section{Perbedaan Pertambahan Bobot Badan (PBB) Heifers dan Steers}

Pertambahan bobot badan sapi impor Brahman Cross heifers dan steers pada berat kedatangan yang berbeda yaitu 200 sampai 300 kg, 300 sampai 400, dan $>400 \mathrm{~kg}$ ditunjukkan pada Tabel 3. Hasil analisis (Tabel 3) menunjukkan

Tabel 3. Perbedaan Pertambahan Bobot Badan (PBB) sapi impor brahman cross heifers dan steers

\begin{tabular}{llcccc}
\hline Berat Datang $(\mathrm{kg})$ & Keterangan & Sig. & Sig. (2-tailed) & t & Mean Difference \\
\hline \multirow{2}{*}{$200-300$} & Equal variances assumed & \multirow{2}{*}{0,935} & 0,991 & $-0,11$ & $-0,007$ \\
& Equal variance not assumed & & 0,991 & $-0,12$ & $-0,007$ \\
\hline \multirow{2}{*}{$300-400$} & Equal variances assumed & \multirow{2}{*}{0,327} & 0,001 & $-8,86$ & $-0,261$ \\
& Equal variance not assumed & & 0,001 & $-9,06$ & $-0,261$ \\
\hline \multirow{2}{*}{$>400$} & Equal variances assumed & \multirow{2}{*}{0,319} & 0,001 & - & $-0,329$ \\
& Equal variance not assumed & & 0,001 & $5,085,30$ & $-0,329$ \\
\hline
\end{tabular}

Sumber: Hasil output IBM SPSS Statistics 26 
bahwa PBB sapi Brahman Cross heifers dan steers pada berat kedatangan 200 sampai 300 $\mathrm{kg}, 300$ sampai $400 \mathrm{~kg}$, dan $>400 \mathrm{~kg}$ memiliki varians data yang homogen, sebab memiliki nilai Sig. Equality of Variances lebih dari 0,05, yaitu masing-masing sebesar 0,$935 ; 0,327$; dan 0,319, sedangkan pada hasil Sig (2-tailed) menunjukkan bahwa PBB sapi Brahmann Cross heifers dan steers pada berat kedatangan 200 sampai $300 \mathrm{~kg}$ tidak memiliki perbedaan signifikan (5\%), sebab 0,935>0,05 Kondisi tersebut didukung oleh hasil analisis pada Tabel 1 dan 2 yang menunjukkan bahwa rata-rata PBB sapi Brahman Cross ialah 1,44 kg baik heifers maupun steers. Agung (2012) menyatakan bahwa PBB dan PBBH sapi Brahman Cross heifers dan steers yang dipelihara selama 60 hari tidak memiliki perbedaan signifikan.

Sapi Brahman Cross heifers dan steers pada berat kedatangan 300-400 dan $>400$ memiliki perbedaan PBB yang signifikan (5\%) berdasarkan hasil analisis (Tabel 3), sebab nilai Sig. (2-tailed) lebih kecil dari 0,05, yaitu masing-masing 0,001. Solehudin dan Hasibuan (2020) menyatakan bahwa PBB sapi Brahman Cross berkisar 1 sampai $1,8 \mathrm{~kg} /$ ekor/hari. Setiyono, Kusuma, dan Rusman (2017) juga menambahkan bahwa umur dan jenis kelamin memiliki pengaruh nyata terhadap PPB, bobot potong, bobot karkas, dan kadar air. Perbedaan PBB sapi Brahman Cross heifers dan steers juga didukung oleh hasil analisis pada Tabel 1 dan 2, yaitu masing-masing memiliki rataan 1,17 dan 1,10 pada PBB sapi Brahman Cross Heifers dengan berat kedatangan 300 sampai 400 $\mathrm{kg}$ dan $>400 \mathrm{~kg}$, sedangkan pada Steers memiliki rataan masing-masing 1,43. Muslim, Nugroho, dan Susilawati (2013) menyatakan bahwa bobot lahir pedet jantan dan betina memiliki perbedaan, dan kondisi tersebut dapat berdampak pada PBB sapi Brahman Cross pada jenis kelamin yang berbeda.

\section{KESIMPULAN}

Pertambahan bobot badan maksimal sapi impor bangsa Brahman Cross jenis heifers pada berat kedatangan (BD) 200, 300, dan 400 kg masing-masing ialah 2,01; 1,81; dan 1,45 kg dengan rata-rata $\mathrm{PBB}$ masing-masing sebesar 1,40; 1,17; dan 1,10 kg, sedangkan PBB maksimal untuk jenis steers pada berat kedatangan (BD) 200, 300, dan $400 \mathrm{~kg}$ masing-masing ialah 1,86; 2,53; dan 1,96 kg dengan rata-rata PBB masingmasing sebesar 1,44; 1,43; dan 1,43 kg. Sapi impor bangsa Brahman Cross jenis steers memiliki PBB lebih tinggi jika dibandingkan dengan jenis heifers. Saran untuk perusahaan importir sapi potong bakalan hendaknya memilih jenis steers pada berat kedatangan (BD) $300 \mathrm{~kg}$, sebab sapi memiliki potensi PBB yang maksimal.

\section{UCAPAN TERIMA KASIH}

Penelitian ini merupakan bagian dari rangkaian penelitian yang panjang dan berkelanjutan, sehingga melibatkan banyak pihak dalam pelaksanaan penelitian ini. Tim penulis menyampaikan ucapan terimakasih kepada: a) Lembaga Penelitian dan Pengabdian kepada Masyarakat (LP2M) Universitas Jember (UNEJ); b) Kelompok Riset (KeRis) Agribisnis dan Agroindustri Peternakan (A2P); c) perusahaan penggemukan sapi (feedlot) yang merupakan perusahaan importir sapi bakalan.

\section{DAFTAR PUSTAKA}

Affandhy, L., Aryogi, \& Tiesnamurti, B. (2014). Perkawinan sapi potong di Indonesia. Badan Penelitian dan Pengembangan Pertanian. Jakarta: IAARD Press: Jakarta.

Agung, S. (2012). Evaluasi Bobot Badan Terhadap Pertambahan Bobot Badan (Pbb) Dan Pertambahan Bobot Badan Harian (Pbbh) Sapi Brahman Cross Steer Dan Heifer. Universitas Brawijaya.

Amam, A., Fanani, Z., Hartono, B., \& Nugroho, B. (2019). Identification of resources in the system of broiler farming business. Jurnal Ilmu Ternak dan Veteriner, 24(3), 135-142. http://dx.doi.org/10.14334/jitv.v24.3.1927.

Amam, A., Fanani, Z., Hartono, B., \& Nugroho, B. A. (2019a). Pengembangan usaha ternak ayam pedaging sistem kemitraan bagi hasil berdasarkan aksesibilitas peternak terhadap sumber daya. Jurnal Ilmu Dan Teknologi Peternakan Tropis, 6(2), 146-153. http:// dx.doi.org/10.33772/jitro.v6i2.5578.

Amam, A., Fanani, Z., Hartono, B., \& Nugroho, B. A. (2019b). Usaha ternak ayam pedaging sistem kemitraan pola dagang umum: Pemetaan sumber daya dan model pengembangan. Sains Peternakan: Jurnal Penelitian Ilmu Peternakan, 17(2), 5-11. https://doi.org/10.20961/sainspet. v17i2.26892.

Amam, A., \& Harsita, P. (2019). Tiga pilar usaha ternak: breeding, feeding, and management. Jurnal Sain Peternakan Indonesia, 14(4), 431439. https://doi.org/10.31186/jspi.id.14.4.431439.

Amam, A., Jadmiko, M. W., Harsita, P. A., \& Yulianto, R. (2019). Internal resources of dairy cattle farming business and their effects on institutional performance and business development. Animal Production, 21(3), 157-166. http://doi.org/10.20884/1. 
jap.2019.21.3.738.

Amam, A., Yulianto, R., Widodo, N., \& Romadhona, S. (2020). Pengaruh aspek kerentanan terhadap aksesibilitas sumber daya usaha ternak sapi potong. Livestock and Animal Research, 18(2), 160-170. https://doi.org/10.20961/lar. v18i2.42955.

Amien, I. (2013). Pertambahan Bobot Badan dan Konversi Pakan Sapi Limousin Cross Dengan Pakan Tambahan Probiotik. Universitas Brawijaya: Malang.

Brew, M., Myer, R., Hersom, M., Carter, J., Elzo, M., Hansen, G., \& Riley, D. (2011). Water intake and factors affecting water intake of growing beef cattle. Livestock Science, 140(1-3), 297-300. https://doi.org/10.1016/j. livsci.2011.03.030.

Daigle, C. L., Mathias, A. J., Ridge, E. E., Gill, R., Wickersham, T. A., \& Sawyer, J. E. (2018). Case study: effect of exercise programs during receiving in a commercial feedlot on behavior and productivity of Brahman crossbred calves: results from a commercial environment and a comparison to the research environment. The Professional Animal Scientist, 34(6), 653-663. https://doi.org/10.15232/pas.2018-01744.

Façanha, D. A. E., Ferreira, J. B., Leite, J. H. G. M., de Sousa, J. E. R., Guilhermino, M. M., Costa, W. P., . . . Silveira, R. M. F. (2019). The dynamic adaptation of Brazilian Brahman bulls. Journal of thermal biology, 81, 128-136. https://doi. org/10.1016/j.jtherbio.2019.02.016.

Fields, M. J., Hentges Jr, J. F., \& Cornelisse, K. W. (1982). Aspects of the sexual development of Brahman versus Angus bulls in Florida. Theriogenology, 18(1), 17-31. https://doi. org/10.1016/0093-691X(82)90045-0.

Firdausi, A., Susilawati, T., Nasich, M., \& Kuswati, K. (2012). Pertambahan bobot badan harian sapi Brahman Cross Pada bobot badan dan frame size yang berbeda. Ternak Tropika, 13(1), 48-62.

Harsita, P., \& Amam, A. (2019). Permasalahan Utama Usaha Ternak Sapi Potong di Tingkat Peternak dengan Pendekatan Vilfredo Pareto Analysis. Paper presented at the Prosiding Seminar Nasional Teknologi Peternakan dan Veteriner.
McAlpine, C. A., Etter, A., Fearnside, P. M., Seabrook, L., \& Laurance, W. F. (2009). Increasing world consumption of beef as a driver of regional and global change: A call for policy action based on evidence from Queensland (Australia), Colombia and Brazil. Global Environmental Change, 19(1), 21-33. https:// doi.org/10.1016/j.gloenvcha.2008.10.008.

Muslim, K. N., Nugroho, H., \& Susilawati, T. (2013). Hubungan antara bobot badan induk dan bobot lahir pedet sapi Brahman cross pada jenis kelamin yang berbeda. Jurnal Ilmu-Ilmu Peternakan, 23(1), 18-24.

Nazir, M. (2014). Metode Penelitian: Ghalia Indonesia: Bogor.

Phillips, W., Holloway, J., Warrington, B., \& Venuto, B. (2009). Stocker and feedlot performance of Beef Heifers Sired by Braunvieh and Wagyu Bulls from Angus-, Brahman-, Senepol-, and Tuli-sired Dams. The Professional Animal Scientist, 25(6), 809-814. https://doi. org/10.15232/S1080-7446(15)30793-2.

Setiawan, H., Hartono, B., \& Utami, H. (2014). Kontribusi pendapatan usaha ternak sapi potong terhadap rumah tangga peternak. Jurnalku, 1(1), 1-10.

Setiyono, S., Kusuma, A., \& Rusman, R. (2017). Pengaruh bangsa, umur, jenis kelamin terhadap kualitas daging sapi potong di Daerah Iswimewa Yogyakarta. Buletin Peternakan, 41(2), 176-186.

Soetriono, S., Soejono, D., Zahrosa, D. B., Maharani, A. D., \& Amam, A. (2019). Strategi pengembangan dan diversifikasi sapi potong di Jawa Timur. Jurnal Ilmu dan Teknologi Peternakan Tropis, 6(2): 138-145. http:// dx.doi.org/10.33772/jitro.v6i2.5571.

Solehudin, S., \& Hasibuan, M. (2020). Kinerja reproduksi sapi Brahman Cross di Kabupaten Batubara. Journal of Livestock and Animal Health, 25(1), 24-34.

Zajulie, M. I., Nasich, M., Susilawati, T., \& Kuswati, K. (2015). Distribusi komponen karkas sapi Brahman Cross (BX) hasil penggemukan pada umur pemotongan yang berbeda. Jurnal Ilmu-Ilmu Peternakan (Indonesian Journal of Animal Science), 25(1), 24-34. 